\title{
Osteomielitis púbica espontánea asociada a actividad física
}

\author{
Ricard Prat-Galitó1, Karen Tinoco-Gómez ${ }^{2}$, Xavier Herranz-Pérez², Lluís Sánchez-Sitges², Andrea Farina² \\ 'Universitat Internacional de Catalunya. Sant Cugat del Vallès, Barcelona. España \\ ${ }^{2}$ Servicio de Medicina Interna. Hospital Universitari General de Catalunya. Sant Cugat del Vallès, Barcelona. España
}

Recibido: 22/02/2021

Aceptado: 25/03/2021

En línea: 30/04/2021

Citar como: Prat-Galitó R, Tinoco-Gómez K, Herranz-Pérez X, Sánchez-Sitges L, Farina A. Osteomielitis púbica espontánea asociada a actividad física. Rev Esp Casos Clin Med Intern (RECCMI). 2021 (abril); 6(1): 39-42. doi: 10.32818/reccmi.a6n1a12.

Cite this as: Prat-Galitó R, Tinoco-Gómez K, Herranz-Pérez X, Sánchez-Sitges L, Farina A. Spontaneous pubic osteomyelitis associated with physical activity. Rev Esp Casos Clin Med Intern (RECCMI). 2021 (April); 6(1): 39-42. doi: 10.32818/reccmi.a6n1a12.

Autor para correspondencia: : Ricard Prat-Galitó. ricardpratg@uic.es

\section{Palabras clave \\ $\triangleright$ Osteomielitis \\ $\triangleright$ Osteítis \\ $\triangleright$ Pubis \\ $\triangleright$ Actividad física \\ $\triangleright$ Staphylococcus aureus}

\begin{tabular}{l} 
Keywords \\
\hline$\triangleright$ Osteomyelitis \\
$\triangleright$ Osteitis \\
$\triangleright$ Pubic Bone \\
$\triangleright$ Exercise \\
$\triangleright$ Staphylococcus aureus
\end{tabular}

\begin{abstract}
Resumen
La osteomielitis púbica es una variante rara de infección ósea que se produce secundariamente a la siembra bacteriana hematógena o por inoculación directa. Clínicamente cursa con dolor púbico agudo intenso, limitación de la marcha, fiebre elevada, leucocitosis y elevación de reactantes de fase aguda. En una minoría de pacientes el cuadro clínico aparece en relación al ejercicio físico vigoroso. El diagnóstico diferencial debe establecerse con la osteítis púbica. Presentamos el caso de una mujer de 15 años, con clínica típica, antecedente de actividad deportiva y hemocultivos positivos para Staphylococcus aureus, como perfil de paciente tipo para esta entidad.
\end{abstract}

\section{Puntos destacados}

$\triangleright$ La osteomielitis púbica es una variante rara de infección ósea que se presenta en una minoría de pacientes en el contexto de ejercicio físico vigoroso.

$\triangleright$ En el caso clínico expuesto se utilizan exploraciones complementarias mínimamente invasivas que sugieren el diagnóstico.

\section{Introducción}

La osteomielitis púbica (OMP) es una variante rara entre las infecciones óseas, que afecta al cuerpo del pubis y a sus ramas. Se trata de una entidad cuya verdadera incidencia es desconocida, aunque se estima que corresponde a menos del $1 \%$ de las osteomielitis ${ }^{1-3}$.

La OMP se origina fundamentalmente por dos mecanismos: la siembra hematógena en el contexto de bacteriemia o la inoculación ósea directa en relación a un proceso quirúrgico'. Sus principales factores de riesgo reconocidos son la cirugía para la incontinencia femenina, actividad deportiva intensa, antecedente de enfermedad maligna pélvica o el uso de drogas intravenosas ${ }^{4}$

\section{Caso clínico}

\section{Antecedentes y enfermedad actual}

Mujer de 15 años de edad con antecedente personal de déficit congénito del plasminógeno, y antecedente materno de miopatía con variante de significado incierto del gen AMPD1.

Acude al servicio de Urgencias por un cuadro de 4 días de evolución consistente en dolor púbico e inguinal izquierdo, imposibilidad para la deambulación, fiebre de hasta $39,8^{\circ} \mathrm{C}$, tiritonas, cefalea intensa y marcado malestar general. Presenta además falta de respuesta a antiinflamatorios no esteroideos. Refiere actividad deportiva de alta intensidad y duración en las dos semanas previas practicando tenis y fútbol.

\section{Exploración física}

A su llegada se encuentra consciente, orientada, normocoloreada, normohidratada y hemodinámicamente estable. Se objetiva dolor selectivo a la palpación en región púbica e inguinal izquierda, así como gran limitación dolorosa 
para la flexión de la cadera, que se incrementa contra resistencia. El resto de la exploración física no muestra hallazgos significativos y no se observan lesiones cutáneas evidentes.

\section{Pruebas complementarias}

La analítica sanguínea al ingreso muestra leucocitosis franca con neutrofilia, trombocitosis reactiva, elevación de fosfatasa alcalina, gamma-glutamil transferasa y alanina aminotransferasa, así como marcado incremento de los reactantes de fase aguda.

La evolución de las determinaciones analíticas se muestra en la Tabla 1.

La radiografía de pelvis en fase aguda no muestra alteraciones significativas a nivel óseo ni de partes blandas (Figura 1).

La resonancia magnética nuclear (RMN) pélvica muestra edema medular óseo extenso en la región periarticular de la sínfisis púbica e irregularidad de las corticales articulares, hallazgos sugestivos de osteítis púbica. Se objetiva la posible desinserción pubiana del tendón del músculo aductor largo izquierdo, con periostitis a nivel perisinfisario izquierdo (Figura 2).

La gammagrafía ósea con tecnecio ${ }^{99}$ revela un acúmulo moderado-intenso de trazador en el pubis izquierdo, con captación en sínfisis púbica y acetábulo izquierdo. La gammagrafía con galio ${ }^{67}$ muestra acúmulo intenso de trazador en la sínfisis púbica, de predominio izquierdo, con ausencia de alteraciones en región acetabular. Conjuntamente, ambas exploraciones sugieren una patología de tipo inflamatorio o infeccioso en pubis izquierdo, compatible con OMP (Figura 3).

Los hemocultivos recogidos durante la evaluación inicial en Urgencias ofrecen un resultado positivo para Staphylococcus aureus meticilina-sensible (SAMS).

Se descarta la endocarditis infecciosa mediante la realización de dos ecocardiogramas transtorácicos, en un intervalo de una semana.

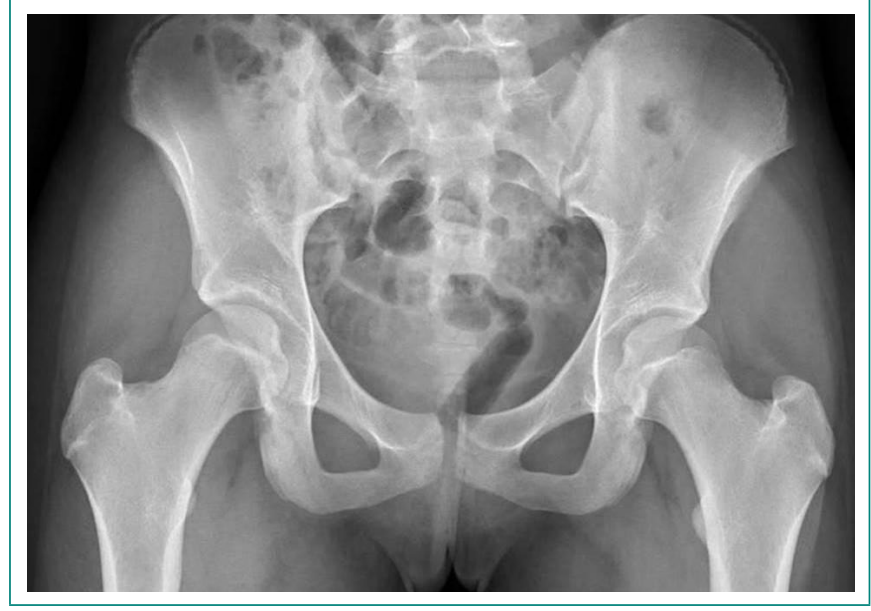

Figura 1. Radiografía pélvica en fase aguda, dentro de la normalidad.

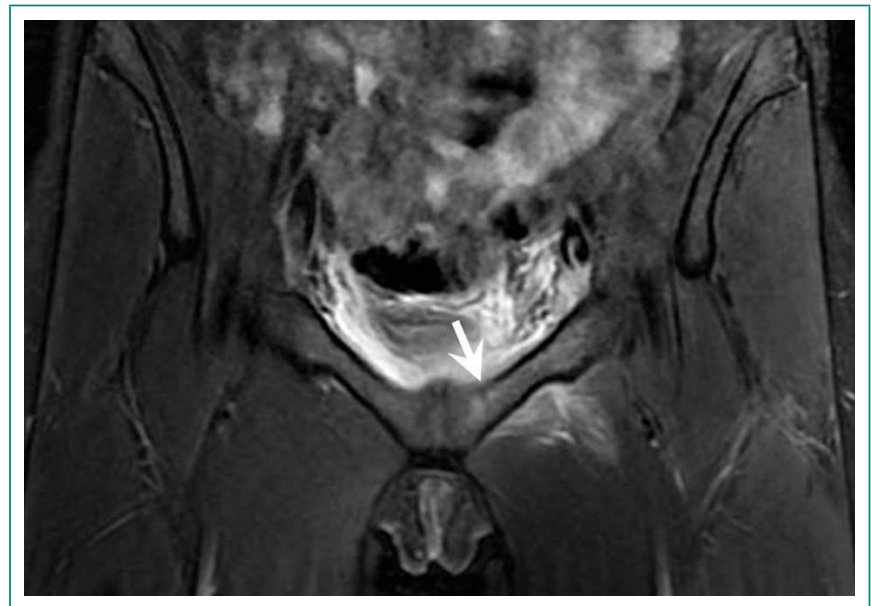

Figura 2. RMN pélvica T2 con supresión grasa, muestra edema medular óseo perisinfisario izquierdo.

\begin{tabular}{|c|c|c|c|c|}
\hline & \\
\hline & & Ingreso & Alta & Referencia \\
\hline \multirow[t]{4}{*}{ Hemoglobina } & Hemoglobina & $11,6 \mathrm{~g} / \mathrm{dL}$ & $11,1 \mathrm{~g} / \mathrm{dL}$ & $12-16 \mathrm{~g} / \mathrm{dL}$ \\
\hline & Leucocitos & $20,7 \times 10^{3} / L$ & $7,0 \times 10^{3} / \mathrm{L}$ & $4,5-13 \times 10^{3} / \mathrm{L}$ \\
\hline & Neutrófilos & $15,3 \times 10^{3} / \mathrm{L}$ & $2,7 \times 10^{3} / \mathrm{L}$ & $1,6-7,5 \times 10^{3} / \mathrm{L}$ \\
\hline & Plaquetas & $554 \times 10^{3} / \mathrm{L}$ & $660 \times 10^{3} / \mathrm{L}$ & $150-450 \times 10^{3} / \mathrm{L}$ \\
\hline \multirow[t]{3}{*}{ Perfil renal y metabólico } & Creatinina & $0,32 \mathrm{mg} / \mathrm{dL}$ & $0,45 \mathrm{mg} / \mathrm{dL}$ & $0,20-1 \mathrm{mg} / \mathrm{dL}$ \\
\hline & Sodio & $139 \mathrm{mmol} / \mathrm{L}$ & $140 \mathrm{mmol} / \mathrm{L}$ & $137-145 \mathrm{mmol} / \mathrm{L}$ \\
\hline & Potasio & $5,0 \mathrm{mmol} / \mathrm{L}$ & $4,8 \mathrm{mmol} / \mathrm{L}$ & $3,5-5,1 \mathrm{mmol} / \mathrm{L}$ \\
\hline \multirow[t]{5}{*}{ Perfil hepático } & Aspartato aminotransferasa & $24 \mathrm{U} / \mathrm{L}$ & $15 \mathrm{U} / \mathrm{L}$ & $5-30 \mathrm{U} / \mathrm{L}$ \\
\hline & Alanina aminotransferasa & $38 \mathrm{U} / \mathrm{L}$ & $20 \mathrm{U} / \mathrm{L}$ & $6-35 U / L$ \\
\hline & Fosfatasa alcalina & $197 \mathrm{U} / \mathrm{L}$ & & $50-130 \mathrm{U} / \mathrm{L}$ \\
\hline & Gamma glutamil transferasa & $192 \mathrm{U} / \mathrm{L}$ & & $<40 \mathrm{U} / \mathrm{L}$ \\
\hline & Bilirrubina total & $0,5 \mathrm{mg} / \mathrm{dL}$ & & $<1,2 \mathrm{mg} / \mathrm{dL}$ \\
\hline \multirow[t]{3}{*}{ Reactantes de fase aguda } & Proteína C reactiva & $17,3 \mathrm{mg} / \mathrm{dL}$ & $1,1 \mathrm{mg} / \mathrm{dL}$ & $<1,0 \mathrm{mg} / \mathrm{dL}$ \\
\hline & Procalcitonina & $0,72 \mathrm{ng} / \mathrm{mL}$ & $0,07 \mathrm{ng} / \mathrm{mL}$ & $<0,5 \mathrm{ng} / \mathrm{mL}$ \\
\hline & Ferritina & $378 \mathrm{ng} / \mathrm{mL}$ & $340 \mathrm{ng} / \mathrm{mL}$ & $6-137 \mathrm{ng} / \mathrm{mL}$ \\
\hline
\end{tabular}

Tabla 1. Evolución analítica. 


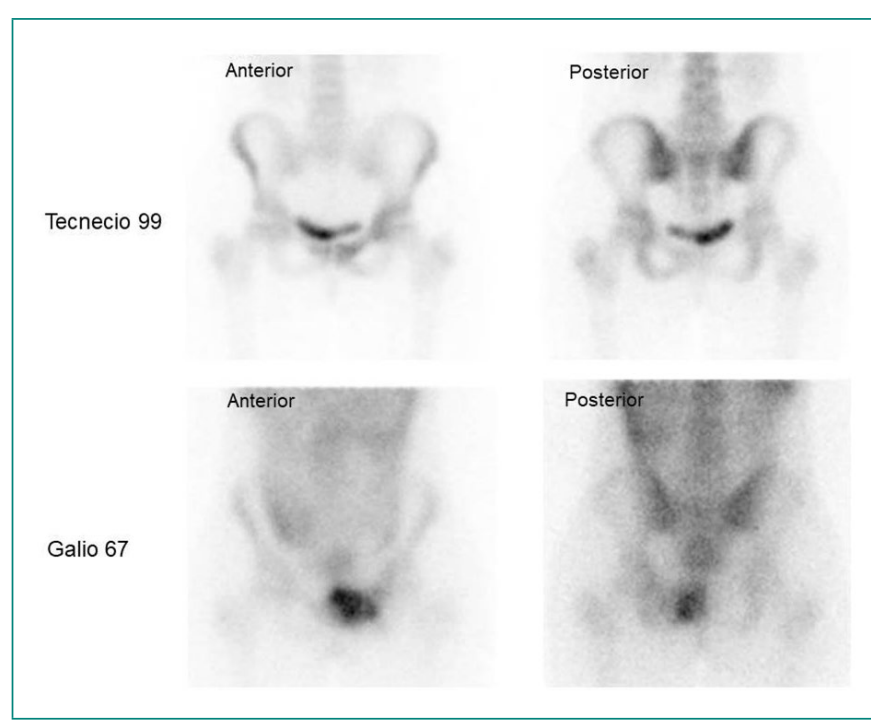

Figura 3. Gammagrafía ósea con tecnecio ${ }^{99}$, muestra acúmulo de trazador en pubis izquierdo, sínfisis púbica y acetábulo izquierdo. Gammagrafía con galio ${ }^{67}$, muestra acúmulo de trazador en sínfisis púbica, predominantemente izquierdo.

\section{Evolución}

Con la sospecha diagnóstica de OMP, se inicia terapia empírica intravenosa con ceftriaxona y linezolid, así como tratamiento analgésico y antipirético sistémico. Tras el inicio de la antibioterapia, la paciente presenta clara mejoría del dolor y de su estado general, y experimenta reducción marcada de la fiebre hasta valores alrededor de $37,2^{\circ} \mathrm{C}$.

Con el resultado del antibiograma, que informa de SAMS, se procede a la desescalada antibiótica para administrar cloxacilina y clindamicina por vía intravenosa. A lo largo de los días restantes de ingreso, la paciente se encuentra afebril, con reducción progresiva del dolor y con rápida mejoría de la movilidad de la extremidad inferior izquierda. Las determinaciones de control muestran una evolución analítica favorable, con reducción gradual de los reactantes de fase aguda, normalización de las alteraciones en el hemograma y de los parámetros hepáticos (Tabla 1).

Finalmente, se le da el alta con tratamiento de cloxacilina oral, que se mantiene hasta completar un total de 6 semanas desde el inicio del cuadro.

\section{Diagnóstico}

Osteomielitis púbica espontánea por Staphylococcus aureus meticilin sensible.

\section{Discusión y conclusión}

La OMP es una forma infrecuente de osteomielitis, cuyo diagnóstico diferencial se debe establecer fundamentalmente con la osteítis púbica (OP). Esta última consiste en una inflamación dolorosa de la sínfisis púbica y sus estructuras adyacentes, de etiología no infecciosa y curso autolimitado. En deportistas se desencadena por un sobreuso de la musculatura con inserción en el pubis y los microtraumatismos derivados ${ }^{4-6}$. Típicamente cursa con dolor púbico que puede irradiar a la ingle y empeora con la deambulación, acompañado de marcha miopática2,4

La distinción de la OMP respecto a la OP recae en la presencia de dolor agudo invalidante y la marcada repercusión sistémica, que consiste en fiebre elevada, malestar general, leucocitosis e incremento de reactantes de fase aguda, así como el resultado positivo en las pruebas microbiológicas ${ }^{3,7}$. Las pruebas de imagen pueden resultar también orientativas en dicha distinción. La RMN se está estableciendo como prueba de referencia por su capacidad para detectar alteraciones precoces y proporcionar una valoración más detallada de la lesión'. Por el contrario, la radiografía simple resulta poco útil dada su incapacidad para detectar cambios en fases iniciales².

Aun así, el caso presentado enfatiza que las exploraciones complementarias son poco específicas de forma aislada, y que sus resultados deben ser interpretados de acuerdo al contexto clínico. En este caso, los hallazgos sugestivos de OP se desestimaron en favor de la OMP, y la desinserción pubiana del músculo aductor largo se descartó clínicamente dada la rápida mejoría de la movilidad tras la antibioticoterapia.

En consonancia con otros autores ${ }^{2,3,8}$ este trabajo demuestra que el diagnóstico de confirmación de OMP se puede establecer, en un contexto clínico sugestivo, tras obtener hemocultivos positivos para un microorganismo compatible. La mejoría de la paciente tras el tratamiento antibiótico específico ratifica esta hipótesis mostrando que las pruebas invasivas como la biopsia ósea no son imprescindibles.

Este caso también concuerda con otros estudios ${ }^{1,4,6}$ en que la infección monobacteriana por Staphylococcus aureus se presenta típicamente en pacientes jóvenes, deportistas y sin comorbilidades asociadas. El antecedente de ejercicio intenso explicaría los microtraumatismos que hacen al pubis más susceptible al asentamiento de microorganismos por siembra hematógena ${ }^{3,6}$. Según Becker et al.', esta es una forma de presentación minoritaria de la OMP, que más frecuentemente aparece en pacientes de alta complejidad, durante el posoperatorio, y con etiología multibacteriana.

La discusión de este caso clínico pretende definir un perfil de paciente tipo, fomentando así el rápido reconocimiento del cuadro pese a su rareza, y la instauración temprana del tratamiento, para evitar posibles complicaciones como el absceso, la extensión a estructuras adyacentes o la inestabilidad pélvica 2,8 .

Como conclusión, e incluso en ausencia de una puerta de entrada evidente, la OMP espontánea se debe considerar ante todo paciente joven que presente de forma aguda pubalgia intensa, fiebre, afectación general, limitación funcional y antecedente de actividad deportiva vigorosa.

\section{Bibliografía}

1. Becker A, Triffault-Fillit C, Valour F, Boussel L, Ruffion A, Laurent F, et al. Pubic osteomyelitis: Epidemiology and factors associated with treatment failure. Med Mal Infect. 2020; 50(8): 684-688. doi: 10.1016/j.medmal.2019.10.012.

2. Andrews JA, Rizzato Lede $D$, Senderovsky M, Finn BC, Emery N, Bottaro F, et al. Artritis séptica del pubis en dos deportistas. Medicina (B Aires). 2012; 72(3): 247-50.

3. Karpos PA, Spindler KP, Pierce MA, Shull HJ Jr. Osteomyelitis of the pubic symphysis in athletes: a case report and literature review. Med Sci Sports Exerc. 1995; 27(4): 473-9.

4. Ross JJ, Hu LT. Septic arthritis of the pubic symphysis: review of 100 cases. Medicine (Baltimore). 2003; 82(5): 340-5. doi: 10.1097/01. md.0000091180.93122.1c.

5. Yax J, Cheng D. Osteomyelitis pubis: a rare and elusive diagnosis. West J Emerg Med. 2014 Nov;15(7):880-2. doi: 10.5811/westjem.2014.8.13401.

6. González-González JC, Payán-Martín L. Osteomielitis en un cuadro de osteopatía púbica. Arch Med Deporte. 2003; 20(95): 259-262. Accesible en: 
http://archivosdemedicinadeldeporte.com/articulos/upload/Caso_clinico-osteomielitis_259_95.pdf (último acceso febrero 2021).

7. Knoeller SM, Uhl M, Herget GW. Osteitis or osteomyelitis of the pubis? A diagnostic and therapeutic challenge: Report of 9 cases and review of the literature. Acta Orthop Belg. 2006; 72(5): 541-548.
8. Gabarró L, Font B, Sala M, Serrate G, Bejarano G, Segura F. Osteítis infecciosa del pubis. Enferm Infecc Microbiol Clin. 2008; 26(6): 345-347. Accesible en: https://www.elsevier.es/es-revista-enfermedades-infecciosas-microbiologiaclinica-28-pdf-S0213005X08727253 (último acceso febrero 2021). 